\title{
Synthesis and Evaluation of Glyceride Prodrugs of Naproxen
}

\author{
Vivekkumar K. Redasani ${ }^{1 *}$, Sanjay B. Bari ${ }^{2}$ \\ ${ }^{1}$ R. C. Patel Institute of Pharmaceutical Education and Research, Shirpur, India \\ ${ }^{2}$ H. R. Patel Institute of Pharmaceutical Education and Research, Shirpur, India \\ Email: *vivek.redasani@gmail.com
}

Received June 14, 2013; revised July 13, 2013; accepted July 28, 2013

Copyright (C) 2013 Vivekkumar K. Redasani, Sanjay B. Bari. This is an open access article distributed under the Creative Commons Attribution License, which permits unrestricted use, distribution, and reproduction in any medium, provided the original work is properly cited.

\begin{abstract}
The glyceride ester derivatives $\mathbf{6 a}$ and $\mathbf{6 b}$ were prepared by reacting 1,2,3-trihydroxy propane 1,3-dipalmitate/stearate with (S)-naproxen as potential prodrugs. The synthesis was achieved successfully with the aid of N,N'-dicyclohexylcarbodiimide. These prodrugs were evaluated for anti inflammatory, analgesic and gastroprotective activity. It was found that prodrugs $\mathbf{6 a}$ and $\mathbf{6 b}$ showed less irritation to gastric mucosa as indicated by ulcer index. The synthesized glyceride esters were found to possess good pharmacological profile as shown by results of anti inflammatory and analgesic activity. The aqueous studies were performed in order to ensure the release of prodrugs. Both prodrugs were found to stable at acidic $\mathrm{pH}$ while underwent hydrolysis at $\mathrm{pH}$ 7.4. These findings suggest that the glyceride prodrugs $\mathbf{6 a}$ and $\mathbf{6 b}$ might be used as potential biolabile derivatives.
\end{abstract}

Keywords: Naproxen; Glyceride Prodrugs; Anti-Inflammatory; Analgesic; Gastroprotective; Hydrolysis Kinetics

\section{Introduction}

The clinical utility of the conventional acidic non-steroidal anti-inflammatory drugs (NSAIDs) continues to be principally limited by their undesired side effects, particularly stomach ulceration, bleeding and perforation [1]. The gastric side effects related to the use of NSAIDs are generally attributed to local and/or systemic mechanisms [2]. This can be overcome to a considerable extent by derivatization of the carboxylic function of the NSAIDs to produce prodrug with adequate stability at the acidic $\mathrm{pH}$, thus preventing local irritation of the stomach mucosa, and also capable of releasing the parent drug [3]. The utility of glyceride as a promoiety in the design of prodrugs of carboxylic acids relates to the absorption of natural triglycerides, thereby increasing stability in the stomach and thus overall absorption of the drug [4].

Naproxen, ((S)-6-methoxy- $\alpha$-methyl-2-naphthalene acetic acid) is one of the most widely used NSAIDs for relieving arthritic pain. Free carboxylic group of naproxen has severe gastrointestinal side effects on oral administration that restricts its use [5]. To overcome this, acidic group is temporarily masked by synthesizing

"Corresponding author. glyceride ester prodrugs, which can pass through the stomach without releasing active drug in significant quantity and also increase the absorption pertaining to the natural triglycerides.

Earlier, the glyceride prodrugs of some NSAIDs like mefenamic acid [4], asprin [6], indomethacin [7], niflumic acid [8], diclofenac [9], ibuprofen [10] and also biphenyl acetic acid [11] were reported. In the present study, we have reported the synthesis of glyceride prodrugs of (S)-naproxen, their evaluation for pharmacological activity and hydrolysis kinetics studies.

\section{Materials and Methods}

\subsection{General Experimental}

Naproxen was obtained as gift sample form Cadila Health Care Ltd., Ahmedabad (India). All other chemicals and reagents were obtained from Loba Chemie Pvt. Ltd., Mumbai (India). Dihydroxyacetone was procured from Merck Specialities Pvt. Ltd., Mumbai (India). All the solvents used were distilled and dried before use as required. Infra red (FTIR) spectra were recorded using KBr on FTIR-8400S Shimadzu. ${ }^{1} \mathrm{H}$ NMR spectra recorded on Joel-FT-NMR-300MHZ in $\mathrm{CDCl}_{3}$ and mass spectra were recorded on HELWETT PACKARD G180017 
GCD system. The chromatographic system consisted of a Shimadzu LC-20 AD solvent delivery system, PDA detector with a Qualisil BDS C8 column $(200 \mathrm{~mm} \times 4.6$ $\mathrm{mm} 5 \mu \mathrm{m})$ using acetonitrile: buffer $(90: 10 \mathrm{v} / \mathrm{v})$ as mobile phase for determination and flow rate of $1.0 \mathrm{~mL} / \mathrm{min}$ with UV detection at $232 \mathrm{~nm}$.

\subsection{Synthesis and Characterization of Title Compounds}

1) Preparation of palmityl steryl chloride (1a and 1b)

Palmitic/steric acid (10 gm) was dissolved in chloroform and treated with thionyl chloride $(10 \mathrm{~mL})$. The reaction mixture was refluxed for $4 \mathrm{hrs}$ at $85^{\circ} \mathrm{C}-90^{\circ} \mathrm{C}$, cooled and filtered to remove unreacted acid. Solvent was evaporated. The oily product was dissolved in absolute ether and evaporated to get corresponding acid chloride (1a and 1b).

2) Preparation of 1,3-dipalmitoyl-1,3-dihydroxy-propane-2-one (3a) and 1,3-distearyl-1,3-dihydroxy-propane2-one (3b)

Palmitoyl chloride/steryl chloride $(20 \mathrm{mmol})$ was added drop wise to reaction media, prepared under stirring at $5^{\circ} \mathrm{C}-10^{\circ} \mathrm{C}$, containing 1,3-hydroxypropane-2-one [DHA] (2) (90 mmol), pyridine $(17 \mathrm{~mL})$ and $\mathrm{CHCl}_{3}$. Reactions were stirred at room temperature for $48 \mathrm{~h}$. Water was added and organic layers were separated. Aqueous layers were extracted with $\mathrm{CHCl}_{3}(3 * 50 \mathrm{~mL})$. Organic layers were joined, washed with water and treated with $0.1 \mathrm{~N} \mathrm{HCl}(3 * 30 \mathrm{~mL})$. The resulting organic layers were separated, dried over anhydrous sodium sulfate, filtered and the solvent was removed under reduced pressure.

3) Preparation of 1,3-dipalmitoyl-1,2,3-propanetriol (4a) and 1,3-distearyl-1,2,3-propanetriol (4b)

Sodium borohydride $(53 \mathrm{mmol})$ was added to reaction media containing $\mathbf{3 a}$ and $\mathbf{3 b}$ respectively $(20 \mathrm{mmol})$ in tetrahydrofurane, benzene and distilled water. Reactions were kept under stirring at $0^{\circ} \mathrm{C}-5^{\circ} \mathrm{C}$, and when presence of reactants was no longer detected through TLC, benzene $(25 \mathrm{~mL})$ and water $(100 \mathrm{~mL})$ were added. Organic layers were separated and aqueous layers extracted with $\mathrm{CHCl}_{3}(25 \mathrm{~mL})$. The combined extracts were washed with water and treated with $0.1 \mathrm{~N} \mathrm{HCl}(15 \mathrm{~mL})$. The resulting organic layer was separated, dried over anhydrous sodium sulfate and solvent evaporated under reduced pressure to get $\mathbf{4 a}$ and $\mathbf{4 b}$.

4) Preparation of glyceride prodrug of naproxen (6a)

Naproxen (5) (1 mmol) and 4a/4b (1.1 mmol) added to reaction media containing 4-DMAP $(0.1 \mathrm{mmol})$ in $\mathrm{CH}_{2} \mathrm{Cl}_{2}$. After homogenization, DCC $(0.0013 \mathrm{~mol})$ in $\mathrm{CH}_{2} \mathrm{Cl}_{2}(100 \mathrm{~mL})$ was added drop wise, and the mixture was kept under stirring at room temperature. After $24 \mathrm{~h}$, the precipitate DCU was filtered and the solvent removed under reduced pressure to get solid mass (Scheme 1) (6a and $\mathbf{6 b}$ ). This was further recrystallized by petroleum ether and characterized.

6a: $\left[\mathrm{C}_{49} \mathrm{H}_{80} \mathrm{O}_{7}\right] \mathrm{mp} 68^{\circ} \mathrm{C}-69^{\circ} \mathrm{C}$, IR $(\mathrm{KBr}) \mathrm{cm}^{-1}: 2915$, 2854 (C-H), 1740 ( $\mathrm{C}=\mathrm{O}$ ester), 1232 (C-O ester). ${ }^{1} \mathrm{H}$ NMR (300 MHz, $\left.\mathrm{CDCl}_{3}\right): \delta(\mathrm{ppm}): 0.96\left(\mathrm{~m}, 6 \mathrm{H}, 2 \mathrm{xCH}_{3}\right)$, $1.29\left(\mathrm{~m}, 24 \mathrm{xCH}_{2}\right), 1.58\left(\mathrm{~s}, 3 \mathrm{H}, \mathrm{CH}_{3}\right), 1.68(\mathrm{~m}, 4 \mathrm{H}$, $2 \mathrm{xCH}_{2}, \beta$ to $\mathrm{CO}$ ), 2.25 ( $\mathrm{m}, 4 \mathrm{H}, 2 \mathrm{xCH}_{2}, \alpha$ to $\mathrm{CO}$ ), 3.73 (s, $\left.3 \mathrm{H},-\mathrm{OCH}_{3}\right), 3.78(\mathrm{~m}, 1 \mathrm{H},-\mathrm{CH}), 4.73(\mathrm{~m}, 1 \mathrm{H},-\mathrm{CH}), 4.32$ $\left(\mathrm{m}, 4 \mathrm{H}, 2 \mathrm{xCH}_{2}\right), 7.18$ - $7.57(6 \mathrm{H}$, naphthalene). Mass: $(70 \mathrm{eV}) \mathrm{m} / \mathrm{z} 780$.

6b: $\left[\mathrm{C}_{53} \mathrm{H}_{88} \mathrm{O}_{7}\right] \mathrm{mp} 104^{\circ} \mathrm{C}-105^{\circ} \mathrm{C}$, IR $(\mathrm{KBr}) \mathrm{cm}^{-1}$ : 2924, 2860 (C-H), 1744 (C = O ester), 1237 (C-O ester). ${ }^{1} \mathrm{H}$ NMR $\left(300 \mathrm{MHz}, \mathrm{CDCl}_{3}\right): \delta(\mathrm{ppm}): \delta 0.94(\mathrm{~m}, 6 \mathrm{H}$, $\left.2 \mathrm{xCH}_{3}\right), \delta 1.31\left(\mathrm{~m}, 28 \mathrm{xCH}_{2}\right), \delta 1.56\left(\mathrm{~s}, 3 \mathrm{H}, \mathrm{CH}_{3}\right), \delta 1.68$ (m, $4 \mathrm{H}, 2 \mathrm{xCH}_{2}, \beta$ to $\left.\mathrm{CO}\right), \delta 2.34\left(\mathrm{~m}, 4 \mathrm{H}, 2 \mathrm{xCH}_{2}, \alpha\right.$ to $\mathrm{CO}), \delta 3.73\left(\mathrm{~s}, 3 \mathrm{H},-\mathrm{OCH}_{3}\right), \delta 3.88(\mathrm{~m}, 1 \mathrm{H},-\mathrm{CH}), \delta 4.32$ $\left(\mathrm{m}, 4 \mathrm{H}, 2 \mathrm{xCH}_{2}\right), \delta 4.84(\mathrm{~m}, 1 \mathrm{H},-\mathrm{CH}), \delta 7.18-7.56(6 \mathrm{H}$, naphthalene). Mass: $(70 \mathrm{eV}) \mathrm{m} / \mathrm{z} 836$.

\subsection{Pharmacological Screening}

Pharmacological activity was done by using Wistar rats of either sex weighing between $150-200 \mathrm{~g}$ and Swiss albino mice weighing between 25 - 35 gm; procured from animal house of the Institute (RCPIPER/IAEC/ 2009-10/14). The paw edema volume was measured with the help of Ugo Basile Plethysmometer (7140). All results were expressed as mean \pm SEM. Statistical evaluation was performed using analysis of variance followed by Dunnett test for sub group comparison.

\subsubsection{Anti-Inflammatory Activity}

The anti-inflammatory activity was evaluated by carrageenan-induced rat paw oedema model [12]. Wistar rats were divided into four groups of six animals each. Group I serve as control and received only vehicle $(0.5 \% \mathrm{w} / \mathrm{v}$ CMC). Group II, III and IV received naproxen $(10 \mathrm{mg} / \mathrm{kg})$ and glyceride prodrugs $\mathbf{6 a}$ and $\mathbf{6 b}$ respectively in dose molecularly equivalent. All compounds were administered through oral gavage. After $30 \mathrm{~min}$ of compound administration, $0.1 \mathrm{~mL}$ of $1 \%$ carrageenan in normal saline was injected into the sub planter region of left hind paw and the edema volume was measured before injection $\left(V_{0}\right)$ and at the interval of every hour up to $6 \mathrm{~h}$. The percentages of swelling inhibition were calculated as:

$\%$ Inhibition $=\left\{\left[\left(V_{t}-V_{0}\right)\right.\right.$ control $-\left(V_{t}-V_{0}\right)$ treated $] /$ $\left(V_{t}-V_{0}\right)$ control $\} \times 100$.

$V_{0}$ and $V_{t}$ are the average volume in the hind paw of the rats before and after treatment respectively.

\subsubsection{Analgesic Activity}

Analgesic activity was carried out using acetic acid induced writhing method [13]. Group I served as a control and received vehicle $1 \%(\mathrm{v} / \mathrm{v})$ Tween- 80 in water at the dose of $10 \mathrm{~mL} / \mathrm{kg}$ of body weight while group II, III and IV received naproxen $(10 \mathrm{mg} / \mathrm{kg})$, glyceride prodrugs 6 a 


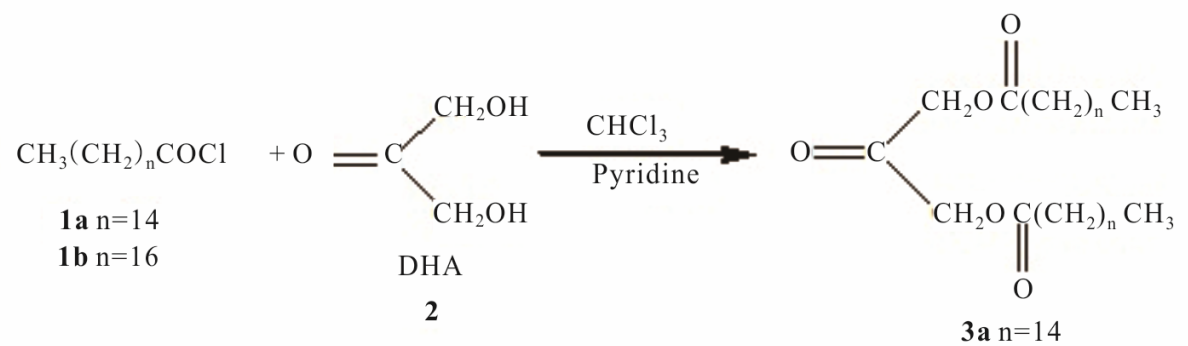

3a $\mathrm{n}=14$<smiles>CCCCCC(=O)CC(C)CC(=O)CC(=O)CC</smiles>

3a $\mathrm{n}=14$

$3 \mathbf{b} n=16$<smiles>CCCCC(C)C(=O)OCC(O)CC(C)=O</smiles>

4a $\mathrm{n}=14$

$4 \mathrm{~b} n=16$<smiles>CCCCC(C)(C)OCC(O)CC(C)=O</smiles>

4a $\mathrm{n}=14$ $4 \mathrm{~b} \mathrm{n}=16$<smiles>COc1ccc2cc(C(C)C(=O)O)ccc2c1</smiles>

5<smiles>CCCCC(C)OC(=O)C(CC(C)=O)C(C)c1ccc2cc(OC)ccc2c1</smiles>

6a $\mathrm{n}=14$

$\mathbf{6 b} \mathrm{n}=16$

Scheme 1. Scheme of synthesis for title compounds 6a and 6b. DHA: dihydroxyacetone; DCC: N,N'-dicyclohexylcarbidiimide; DMAP: 4-dimethylamino pyridine; DCM: dichloromethane.

and $\mathbf{6 b}$ respectively in the dose molecularly equivalent. Acetic acid $(0.7 \%)$ at a dose of $0.1 \mathrm{~mL} / 10 \mathrm{~g}$ was administered intraperitoneally $40 \mathrm{~min}$ after oral administration of the test compounds. After an interval of $10 \mathrm{~min}$, numbers of writhing were counted for $10 \mathrm{~min}$. Analgesic activity was measured as percent decrease in writhing in comparison to control and calculated as:

Percent inhibition of writhing $=(1-\mathrm{Wt} / \mathrm{Wc}) \times 100$. Where, Wc and Wt are average number of writhing produced by control and test groups. 


\subsubsection{Evaluation of Gastroprotective Effect}

Gastro protective effect was determined by the reported method [14]. The animals were given orally $40 \mathrm{mg} / \mathrm{kg}$ body weight of naproxen or molecular equivalent of glyceride prodrugs $\mathbf{6 a}$ and $\mathbf{6 b}$ as suspension in $0.5 \%$ acacia. The animals were fasted $24 \mathrm{~h}$ prior to administration of each of control, standard and test compounds. The animals were sacrificed $6 \mathrm{~h}$ after administration of drug and food and water were available ad libitum. The gastric mucosa was opened, rinse with $5 \mathrm{~mL}$ saline and was examined by means of $4 \times$ binocular magnifier. The stomachs were carefully examined and ulcers were scored according to severity. The ulcer index was calculated as mean for all animals in the group.

\subsection{In Vitro Hydrolysis Studies}

The in-vitro aqueous hydrolysis kinetics studies of prodrugs $\mathbf{6 a}$ and $\mathbf{6 b}$ were carried out at $\mathrm{pH}$ 7.4. The total buffer concentration was $20 \mathrm{mmol}$ and constant ionic strength of $0.5 \mathrm{M}$ for each sample was maintained by adding $\mathrm{KCl}$. Hydrolysis of prodrugs was initiated by adding the samples to buffer solution. The mixtures were equilibrated at $37^{\circ} \mathrm{C}$ for $1 \mathrm{~h}$ and $100 \mathrm{mg}$ of each sample was added. The samples were withdrawn at appropriate time interval $(0.5,1,2,3,4,5,6,7,8 \mathrm{~h}), 0.1 \mathrm{~mL}$ of solution was removed and diluted with mobile phase up to 10 $\mathrm{mL}$ and $20 \mu \mathrm{l}$ of this solution was injected for analysis by HPLC [15]. Pseudo first-order rate constants $\left(\mathrm{K}_{\mathrm{obs}}\right)$ for the individual reactions were calculated with the help of equation, $\mathrm{K}_{\mathrm{obs}}=2.303 / t \times \log (a / a-x)$, Where, " $a$ " is initial concentration, " $x$ " is the amount of drug hydrolyzed and " $t$ " is time in minutes. The corresponding half-life $\left(t_{1 / 2}\right)$ was then obtained from the equation: $t_{1 / 2}=0.693 / \mathrm{K}_{\text {obs }}$.

\section{Results and Discussion}

\subsection{Chemistry}

Triglycerides being the major constituents of dietary fat and their absorption involve simple hydrolysis mainly by pancreatic lipases to monoglycerides and free fatty acids. These prodrugs, therefore, do not involve the risk of unwanted effects after they are hydrolyzed and release promoiety [6].

The synthesis of targeted glyceride esters of naproxen 6a and $\mathbf{6 b}$ was achieved successfully using DCC as per the method reported [16]. DCC proves to be an effective catalyst for the conversion of carboxylic acid to esters and amides. It functions by activating the free carboxylic groups [17]. The purity and confirmation of structures of the synthesized compounds were confirmed by TLC, FTIR, ${ }^{1}$ HNMR and mass spectroscopy. Infrared spectra showed the characteristics band of $\mathrm{C}=\mathrm{O}$ stretching around $1740 \mathrm{~cm}^{-1}$ and $\mathrm{C}-\mathrm{O}$ stretching around $1232 \mathrm{~cm}^{-1}$ which confirms the formation of esters. The ${ }^{1} \mathrm{H}$ NMR spectra of synthesized compounds showed characteristic chemical shifts, which anticipated their structures. Presence of parent peak in mass spectra further confirms the molecular weight.

\subsection{Pharmacological Screening}

Carrageenan-induced paw oedema is a useful model to assess the contribution of mediators involved in vascular changes associated with acute inflammation. The inhibition of swelling in carrageenan-induced edema in rat paw is brought by oral administration of drugs. The development of edema in the rat hind paw following the injection of carrageenan has been described as a biphasic event in which various mediators operate in sequence to produce this inflammatory response. Prodrugs $\mathbf{6 a}$ and $\mathbf{6 b}$ demonstrate better anti-inflammatory activity with percentage inhibition of $58 \%$ and $55 \%$ in comparison to $51 \%$ for naproxen when studied up to $6 \mathrm{~h}$. Increased anti-inflammatory effect observed for glyceride derivatives might be the result of either better absorption of esters from the gastrointestinal tract or due to higher selectivity towards the COX-2 enzyme than the parent drug [18].

The decrease in number of writhing expressed as percentage protection by test compounds with reference to the control for analgesic activity. Glyceride derivatives showed high value of percentage protection with $75 \%$ and $74 \%$ respectively as compared to naproxen with $70 \%$. The abdominal constriction response induced by acetic acid is a sensitive procedure to establish peripherally acting analgesics. Results of analgesic activity of prodrugs shows better as compared to parent drug indicated successful effects of derivatization [19].

The synthesized prodrugs showed less ulcer index value of 0.91 and 1.33 as compared to 2.83 for naproxen thus indicates minimized gastrointestinal side effects obtained by modification to prodrug. This might be due to inhibition of direct contact of carboxylic group of naproxen to gastric mucosa; mainly responsible for gastric damage. This also supports to the successful masking of carboxylic group of naproxen when coupled with that of promoieties thus protect the gastric mucosa from injury evoked.

\subsection{In Vitro Hydrolysis Studies}

The hydrolysis kinetics studies were carried out in aqueous buffer to determine the fate of prodrugs. Under the experimental conditions the targeted compounds hydrolyzed to release the parent drug as evident by HPLC analysis. At constant $\mathrm{pH}$ and temperature the reaction displayed strict first order kinetics as the $\mathrm{K}_{\mathrm{obs}}$ was fairly constant and a straight plot was obtained on plotting log concentration of residual prodrug $v / s$ time (Figure 1). 


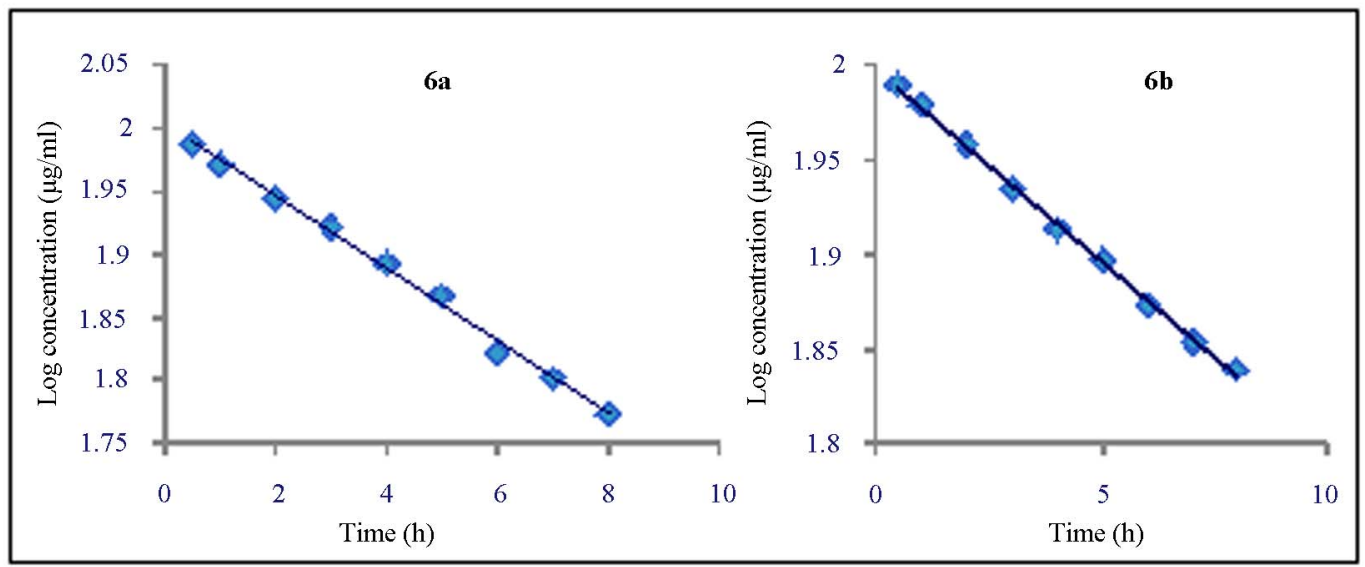

Figure 1. First order hydrolysis plot of naproxen prodrugs $6 \mathrm{a}$ and $6 \mathrm{~b}$ in phosphate buffer pH 7.4.

Table 1. Biological activity and in vitro hydrolysis studies of glyceride prodrugs.

\begin{tabular}{|c|c|c|c|c|c|c|c|c|c|c|}
\hline \multirow{3}{*}{ Compounds } & \multicolumn{8}{|c|}{ Biological activity $^{*}$} & \multirow{2}{*}{\multicolumn{2}{|c|}{$\begin{array}{c}\text { In vitro } \\
\text { hydrolysis study }\end{array}$}} \\
\hline & \multicolumn{6}{|c|}{ Anti-inflammatory activity (\% inhibition) ${ }^{\mathrm{a}}$} & \multirow{2}{*}{ Ulcer index ${ }^{a}$} & \multirow{2}{*}{$\begin{array}{l}\text { Analgesic } \\
\text { activity }^{\mathrm{a}}\end{array}$} & & \\
\hline & $1 \mathrm{~h}$ & $2 \mathrm{~h}$ & $3 \mathrm{~h}$ & $4 \mathrm{~h}$ & $5 \mathrm{~h}$ & $6 \mathrm{~h}$ & & & $\mathrm{~K}_{\mathrm{obs}}$ & $\mathrm{t}_{1 / 2}(\min )$ \\
\hline Naproxen & $20.39 \pm 0.77$ & $32.69 \pm 1.29$ & $41.74 \pm 0.80$ & $49.60 \pm 0.82$ & $51.82 \pm 0.45$ & $51.74 \pm 0.43$ & $2.83 \pm 0.16$ & $70.70 \pm 4.93$ & - & - \\
\hline 6a & $26.74 \pm 0.39$ & $39.48 \pm 0.75$ & $46.88 \pm 0.37$ & $52.34 \pm 0.48$ & $57.00 \pm 0.54$ & $58.69 \pm 0.37$ & $0.91 \pm 0.20$ & $75.87 \pm 5.76$ & $1.04 \times 10^{-3}$ & 664.30 \\
\hline 6b & $24.04 \pm 0.40$ & $30.11 \pm 0.37$ & $42.58 \pm 0.30$ & $48.75 \pm 0.46$ & $53.05 \pm 0.38$ & $55.04 \pm 0.50$ & $1.33 \pm 0.21$ & $74.15 \pm 4.42$ & $8.03 \times 10^{-4}$ & 862.48 \\
\hline
\end{tabular}

*Data represented as mean $\pm \mathrm{SEM}, \mathrm{n}=6$. ${ }^{\mathrm{a}}$ Statistical analysis was performed with ANOVA followed by Dunnett test $\mathrm{P}<0.01$ with respect to control; ${ }^{\mathrm{b}}$ at $\mathrm{pH} 7.4$ and $37^{\circ} \mathrm{C}$.

The rate constant $\left(\mathrm{K}_{\mathrm{obs}}\right)$ and the corresponding half-lives $\left(t_{1 / 2}\right)$ for the respective prodrugs $\mathbf{6 a}$ and $\mathbf{6 b}$ were calculated and found to be $664 \mathrm{~min}$ and $862 \mathrm{~min}$ respectively (Table 1). The release of drug at $\mathrm{pH} 7.4$ indicates that the prodrugs were resistant to acidic environment as desired but would release the parent drug in the system. The obtained values of $t_{1 / 2}$ suggests a slow and sustained release in the body and hence effective for longer duration [4].

\section{Conclusion}

The present work utilizes triglycerides for coupling with naproxen to design prodrugs. The glyceride prodrugs of naproxen were synthesized and characterized successfully. The prodrugs were found to be significantly less ulcerogenic compared to parent drug indicating that gastrointestinal toxicity was due to direct contact of free carboxylic group, which is reduced with enhanced antiinflammatory and analgesic activity. The prodrugs release naproxen quantitatively at $\mathrm{pH} 7.4$ but resistant to hydrolysis at acidic $\mathrm{pH}$. Thus, glyceride prodrug approach is found to be the suitable method for increasing effectiveness of naproxen which was limited due to its undesirable effects.

\section{Acknowledgements}

The authors are thankful to Cadila Health Care Ltd., Ahmedabad (India) for providing gift sample of naproxen.

\section{REFERENCES}

[1] P. K. Halen, P. R. Murumkar, R. Giridhar and M. R. Yadav, "Prodrug Designing of NSAIDs," Mini-Reviews in Medicinal Chemistry, Vol. 9, No. 1, 2009, pp. 124-139. doi:10.2174/138955709787001695

[2] J. R. Vane, Y. S. Bakhle and R. M. Bolting, "Cycloxygenase 1 and 2," Annual Review of Pharmacology and Toxicology, Vol. 38, No. 1, 1998, pp. 97-102. doi:10.1146/annurev.pharmtox.38.1.97

[3] N. Bodor, "Retrometabolic Approaches for Drug Design and Targeting," Pharmazie, Vol. 52, No. 7, 1997, pp. 491-494.

[4] M. S. Y. Khan and M. Akhter, "Glyceride Derivatives as Potential Prodrugs: Synthesis, Biological Activity and Kinetic Studies of Glyceride Derivatives of Mefenamic Acid," Pharmazie, Vol. 60, No. 2, 2005, pp. 110-114.

[5] P. Sharma, S. Yadav, R. Pahwa, D. Kaushik and S. Jain, "Synthesis and Evaluation of Novel Prodrugs of Napro- 
xen," Medicinal Chemistry Research, Vol. 20, No. 5, 2011, pp. 648-655. doi:10.1007/s00044-010-9364-8

[6] G. Y. Paris, D. L. Garmaise, D. G. Cimon, L. Swett, G. W. Carter and P. Young, "Glycerides as Prodrugs: Synthesis and Antiinflammatory Activity of 1,3-Bis(alkanoyl)-2-(O-acetylsalicyloy) Glycerides (Aspirin Triglycerides)," Journal of Medicinal Chemistry Vol. 22, No. 6, 1979, pp. 683-687. doi:10.1021/jm00192a014

[7] G. Y. Paris, D. L. Garmaise and D. G. Cimon, "Glycerides as Prodrugs. 3. Synthesis and Antiinflammatory Activity of [1-(p-Chlorobenzoyl)-5-methoxy-2-methylindole-3-acetyl]glycerides (Indomethacin Glycerides)," Journal of Medicinal Chemistry, Vol. 23, No. 1, 1980, pp. 912. doi:10.1021/jm00175a003

[8] L. El Kihel, J. Bourass, P. Richomme, J. Y. Petit and Y. Letourneux, "Synthesis and Antiinflammatory Activity of Niflumic Acid Lipophilic Prodrugs in Brain Edema," Arzneimittel-Forschung/Drug Research, Vol. 46, No. 11, 1996, pp. 1040-1044.

[9] M. S. Y. Khan and M. Akhter, "Synthesis, Biological Evaluation and Kinetic Studies of Glyceride Prodrugs of Diclofenac," Indian Journal of Experimental Biology, Vol. 42, No. 11, 2004, pp. 1066-1072.

[10] M. S. Y. Khan and M. Akhter, "Synthesis, Pharmacological Activity and Hydrolytic Behavior of Glyceride Prodrugs of Ibuprofen," European Journal of Medicinal Chemistry, Vol. 40, No. 4, 2005, pp. 371-376. doi:10.1016/i.ejmech.2004.11.009

[11] M. S. Y. Khan, M. Akhter and A. Husain, "Synthesis Biological Evaluation and Kinetic Studies of Glyceride Prodrugs of Biphenyl Acetic Acid," Indian Journal of Chemistry, Vol. 45B, No. 4, 2006, pp. 1014-1019.

[12] C. A. Winter, E. A. Risley and G. W. Nuss, "CarrageeninInduced Edema in Hind Paw of the Rat as an Assay for Anti Inflammatory Drugs," Proceedings of the Society for Experimental Biology and Medicine, Vol. 111, 1962, pp. 544-547.
[13] M. R. Yadav, M. N. Datta, A. Ananthakrishnan, S. B. Pathik, T. S. Shrikant, G. Rajani, P. Arvind and R. Balaraman, "Synthesis of New Chemical Entities from Paracetamol and NSAIDs with Improved Pharmacodynamic Profile," Bioorganic \& Medicinal Chemistry, Vol. 14, No. 24, 2006, pp. 8701-8706. doi:10.1016/j.bmc.2006.08.017

[14] V. Cioli, S. Putzolu, V. Rossi, P. S. Barcellona and C. Corradino, "The Role of Direct Tissue Contact in the Production of Gastrointestinal Ulcers by Anti-Inflammatory Drugs in Rats," Toxicology and Applied Pharmacology, Vol. 50, No. 2, 1979, pp. 283-287. doi:10.1016/0041-008X(79)90153-4

[15] B. T. Ali, F. M. Monther and H. M. Mohammed, "Design, Synthesis and Hydrolysis Study of Mutual Prodrugs of NSAIDs with Different Antioxidants via Glycolic Acid Spacer," International Journal of Comprehensive Pharmacy, Vol. 1, No. 3, 2012, p. 3.

[16] M. F. Zaida, P. S. Elisabete, F. R. Jo, M. D. Gisela and C. S. G. Jos, "A New Sunscreen of the Cinnamate Class: Synthesis and Enzymatic Hydrolysis Evaluation of Glyceryl Esters of P-Methoxycinnamic Acid," European Journal of Pharmaceutical Sciences, Vol. 25, No. 1, 2005, pp. 67-72. doi:10.1016/j.ejps.2005.01.018

[17] V. K. Redasani and S. B. Bari, "Synthesis and Evaluation of Mutual Prodrugs of Ibuprofen with Menthol, Thymol, and Eugenol," European Journal of Medicinal Chemistry, Vol. 56, 2012, pp. 134-138. doi:10.1016/j.ejmech.2012.08.030

[18] A. Mishra, R. Veerasamy, P. K. Jain, V. K. Dixit and R. K. Agrawal, "Synthesis, Characterization and Pharmacological Evaluation of Amide Prodrugs of Flurbiprofen," Journal of the Brazilian Chemical Society, Vol. 19, No. 1, 2002, pp. 89-100.

[19] N. Voilley, "Acid-Sensing Ion Channels (ASICs): New targets for the Analgesic Effects of NSAIDs," Current Drug Target-Inflammation \& Allergy, Vol. 3, No. 1, 2004, pp. 71-79. 